\title{
Chronic granulomatous disease: value of the newer imaging modalities
}

\author{
D. D. Stricof, G. M. Glazer and M.A. Amendola \\ Department of Radiology, University of Michigan Medical Center, Ann Arbor, Michigan, USA
}

\begin{abstract}
The contribution of computed tomography (CT), ultrasound (US), and nuclear medicine studies in the evaluation and management of seven patients with chronic granulomatous disease was retrospectively reviewed. These modalities proved valuable in detecting sites of infection, particularly in the abdomen. Three patients had liver abscesses, two had suppurative retroperitoneal lymphadenopathy, one had empyema, and one had a scrotal abscess. Furthermore, CT or US-guided percutaneous aspiration and/or drainage of infected material was successfully performed on three separate occasions in a single patient, obviating the need for surgery. The newer imaging modalities are useful in the prompt diagnosis and in some instances non-operative therapy of complications of chronic granulomatous disease.
\end{abstract}

The child with chronic granulomatous disease (CGD) is predisposed to recurrent infection in multiple sites including the skin, respiratory tract, lymph nodes, liver, spleen, and bone. Often the disease is not diagnosed until after repeated bouts of infection. Although conventional radiography can demonstrate sites of infection, it generally detects advanced disease particularly in the abdomen.

The newer imaging modalities of computed tomography (CT), ultrasound (US), and nuclear medicine have added new dimensions to the radiologic evaluation of the patient with CGD. In this report we present our experience using these modalities in seven patients with CGD.

\section{Methods}

The medical records of seven living unrelated male patients with CGD were reviewed. Each patient had nitroblue tetrazolium dye reduction tests diagnostic of the disease. Radiologic studies of all patients were analyzed with particular emphasis on CT, US, and nuclear medicine studies. CT of the abdomen was performed on four patients using a General Electric $8800 \mathrm{CT} / \mathrm{T}$ scanner; contiguous one centimeter thick sections were obtained after administration of oral and intravenous contrast. Nuclear medicine studies were obtained in all seven patients; ${ }^{67} \mathrm{Ga}$-citrate scans were obtained in five patients, a testicular scan using ${ }^{99 \mathrm{~m}} \mathrm{Tc}$-pertechnetate was obtained in one patient, and six patients had ${ }^{99 m} \mathrm{Tc}$-sulfur colloid liver- spleen scans. Ultrasound examinations were performed on all seven patients using commercially available static or realtime scanners with either 3.5 or $5.0 \mathrm{mHz}$ transducers. On three separate occasions in a single patient, percutaneous interventional procedures guided by US or CT were performed.

\section{Results}

Of the seven patients studied, all had recurrent pneumonias, three had liver abscesses, three had osteomyelitis, two had suppurative retroperitoneal adenopathy, one had empyema (Patient 4), and one had a scrotal abscess (Patient 5). A more detailed summary of the clinical data is presented in Table 1. Although conventional roentgenograms were accurate in evaluating pulmonary and skeletal disease, they were not useful in identifying intraabdominal sites of infection. In the three patients with liver abscesses, ultrasonography detected all lesions (Fig. 1a). CT, ${ }^{67} \mathrm{Ga}$-citrate, and ${ }^{99 \mathrm{~m}} \mathrm{Tc}$-sulfur colloid scans were performed in two of these patients and demonstrated intrahepatic lesions in each (Fig. 1 b). In one of these patients with liver abscess ${ }^{67} \mathrm{Ga}$ scanning also demonstrated an empyema (Fig. 1c). Retroperitoneal lymphadenopathy was detected by ultrasound in two patients. A scrotal abscess was localized by both ultrasound and ${ }^{99 m}$ Tc-pertechnetate scintigraphy in one patient. Hepatosplenomegaly was present in all patients. CT scanning demonstrated hepatic calcifications in three of four patients scanned (Fig. 2); these calcifications were visible on abdominal radiographs in only one patient. 
Table 1. Clinical data summary

\begin{tabular}{|c|c|c|c|c|c|c|}
\hline Patient & Age/age at Diagnosis & Pneumonia & $\begin{array}{l}\text { Suppurative } \\
\text { retroperitoneal } \\
\text { lymphadenopathy }\end{array}$ & $\begin{array}{l}\text { Skin } \\
\text { infection }\end{array}$ & $\begin{array}{l}\text { Liver } \\
\text { abscess }\end{array}$ & Osteomyelitis \\
\hline 1 & 25 years $/ 8$ years & $(+)$ & $(-)$ & $(+)$ & $(+)$ & $(+)$ \\
\hline 2 & 15 years $/ 7$ years & $(+)$ & $(+)$ & $(+)$ & $(+)$ & $(-)$ \\
\hline 3 & 14 years $/ 1$ year & $(+)$ & $(-)$ & $(+)$ & $(-)$ & $(+)$ \\
\hline 4 & 11 years $/ 3$ years & $(+)$ & $(-)$ & $(+)$ & $(-)$ & $(+)$ \\
\hline 5 & 9 years $/ 7$ years & $(+)$ & $(-)$ & $(+)$ & $(+)$ & $(-)$ \\
\hline 6 & 3 years $/ 1$ year & $(+)$ & $(-)$ & $(+)$ & $(-)$ & $(-)$ \\
\hline 7 & 1 year $/ 5$ months & $(+)$ & $(+)$ & $(+)$ & $(-)$ & $(-)$ \\
\hline
\end{tabular}

a Patients 1-6 also had suppurative lymphadenopathy in cervical, inguinal, or other peripheral locations
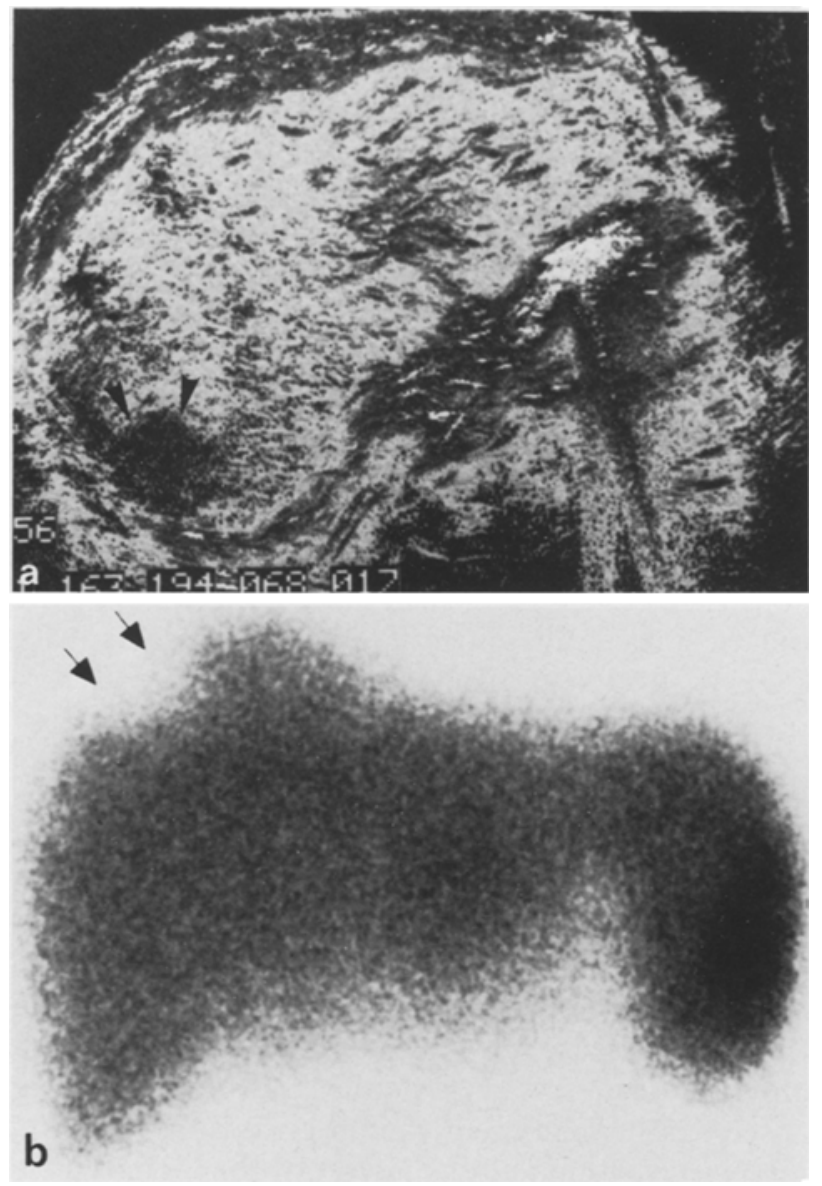

Fig. 1a-c. Patient 5. a Transverse sonogram shows abscess (arrowheads) in posterior segment right lobe of liver. b Posterior view of liver from ${ }^{99 \mathrm{~m}} \mathrm{Tc}$-sulfur colloid scan reveals photon deficient area (arrows). c Posterior and right lateral views from ${ }^{67} \mathrm{Ga}$ citrate scan show hepatic abscess (arrowheads) and empyema (arrows)

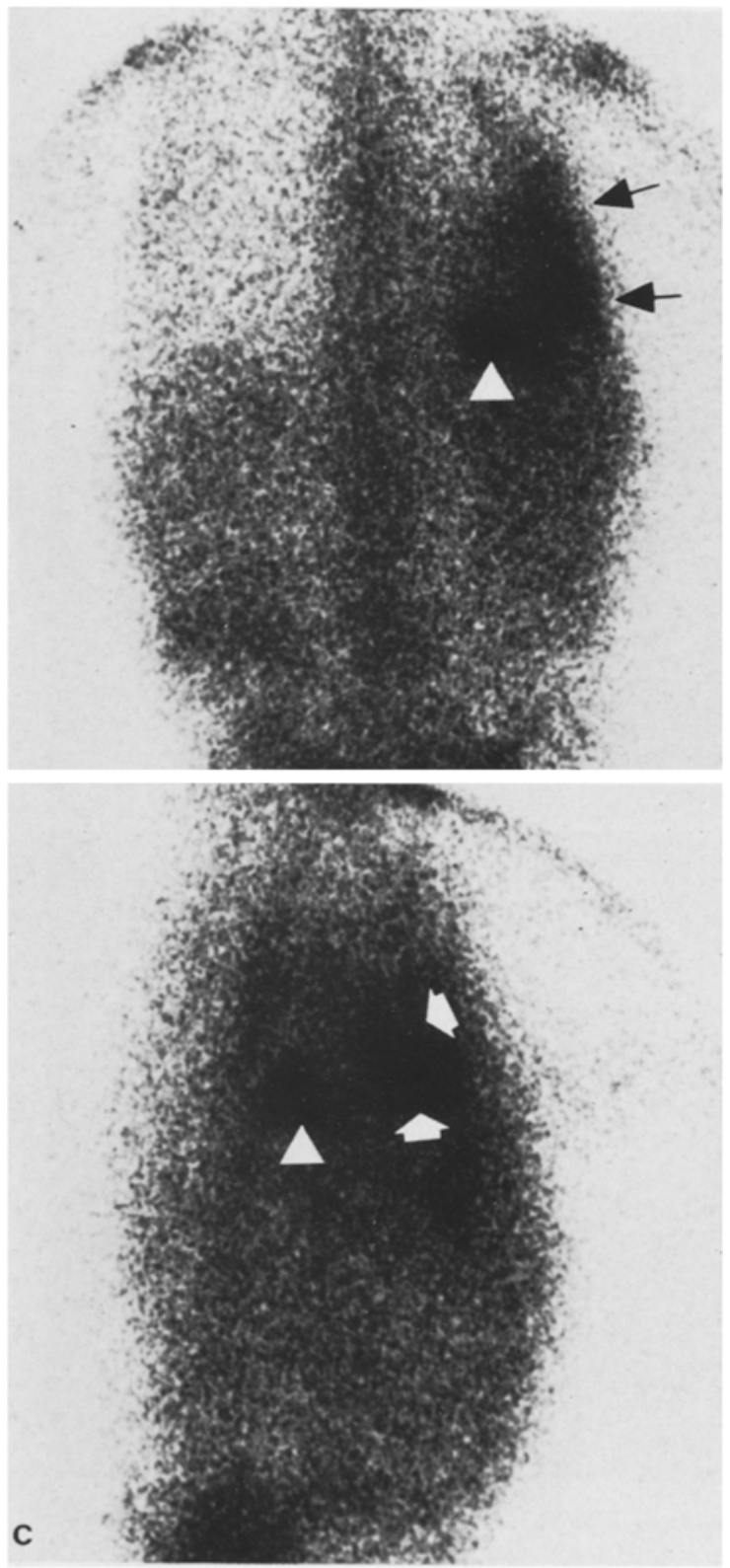




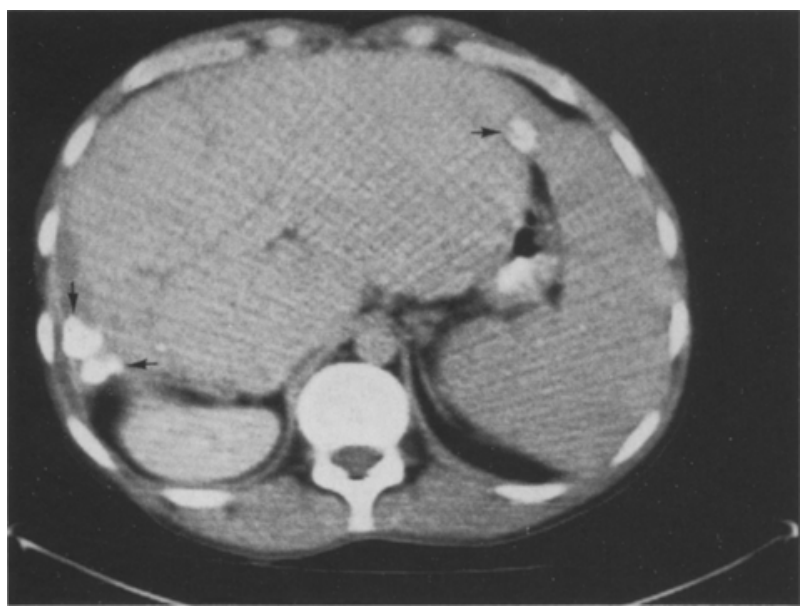

Fig. 2. Patient 1. CT scan shows hepatosplenomegaly and liver calcifications (arrows)
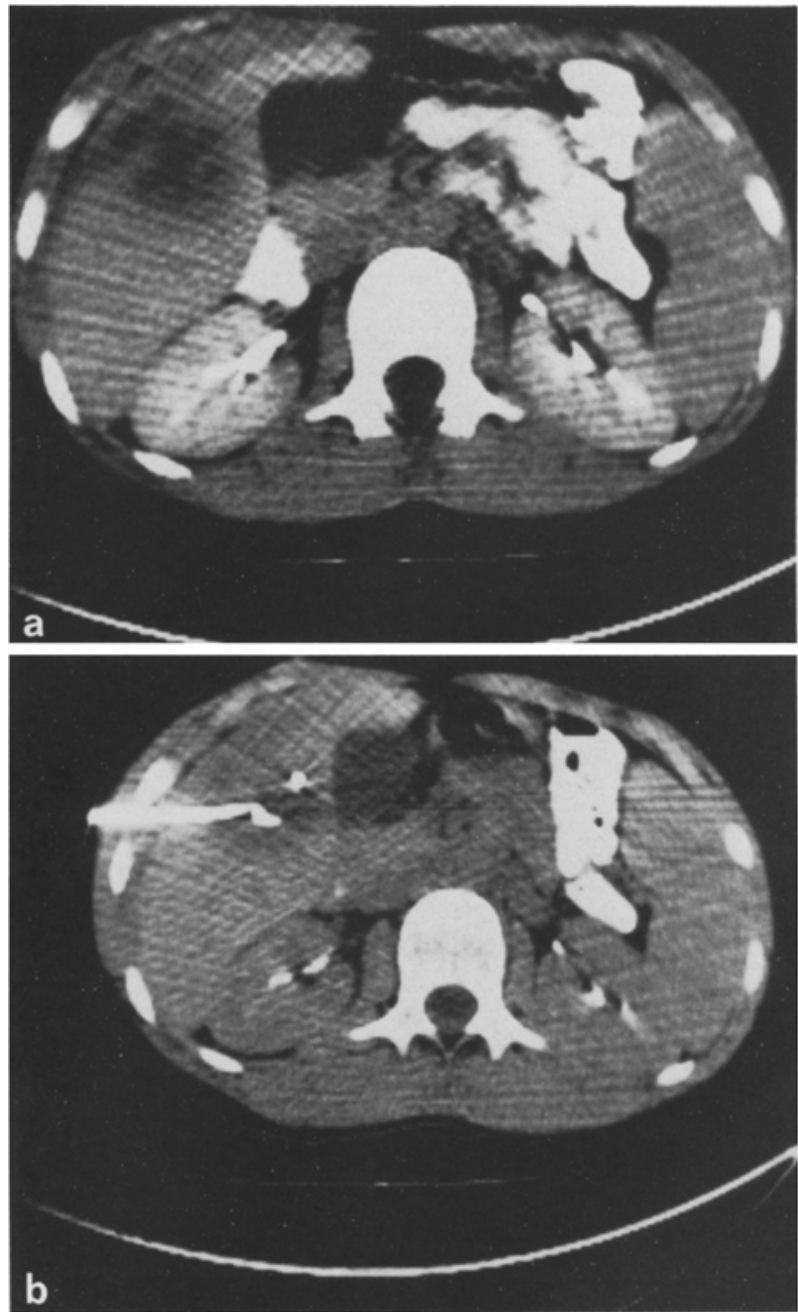

Fig. 3a and b. Patient 2. a Initial CT scan shows hepatic abscess. b Pigtail drainage catheter placed under CT guidance
In one patient three separate interventional radiologic procedures were performed. Initially a liver abscess was percutaneously aspirated under ultrasound guidance and subsequently successfully drained with a pigtail catheter placed using CT (Fig. 3). Several months later an enlarged retroperitoneal lymph node was demonstrated and aspirated using ultrasound; subsequent culture of the aspirated material yielded serratia marcescen. Appropriate antibiotic therapy was instituted with resolution of the suppurative adenopathy.

\section{Discussion}

In chronic granulomatous disease, recurrent infections occur secondary to the inability of the patient's polymorphonuclear leukocytes to destroy certain ingested bacteria and fungi. The inability to kill derives from defective hydrogen peroxide formation due to a variety of enzymatic abnormalities [17, 18]. A granulomatous tissue reaction to infection is the consequence of the abnormality of leukocyte function. In their review of 168 cases reported through 1970 , Johnston and Newman found 144 boys and 24 girls affected by the disease [12].

The general radiographic findings in CGD have previously been described by several authors $[2,4$, 7-9, 20-22]. Since these earlier reports, the newer imaging modalities of CT, US, and nuclear medicine have provided additional means of diagnosing infection. However, there is very little written about the use of these modalities evaluating patients with CGD $[5,10,15,16,19]$.

Review of our data indicates that these modalities can make very significant contributions to the management of patients with CGD. In particular, they have proved useful in evaluating intraabdominal pathology including liver abscesses and retroperitoneal lymphadenopathy previously not detected using conventional radiography. Although laboratory testing is necessary to confirm a diagnosis of CGD, the disease may first be suggested by the radiologist if recurrent pneumonias, osteomyelitis, liver abscess or hepatic calcifications are present.

We have found ultrasonography the preferred exam for suspected intraabdominal complications of CGD. The technique is very sensitive in detecting intrahepatic fluid-filled lesions and can also evaluate extra-hepatic sites including the retroperitoneal lymph nodes and peritoneal recesses for abscess. Other advantages of ultrasonography include ready availability, lack of ionizing radiation, and low cost. Ultrasonography accurately detected complications of CGD in all five of our patients with intraabdominal infection. 
The nuclear medicine agents, ${ }^{131} \mathrm{I}$-rose bengal and ${ }^{99 \mathrm{~m}}$ Tc-sulfur colloid, have been reported useful in evaluating the liver in patients with CGD $[5,16$, 19]. In our experience ${ }^{67} \mathrm{Ga}$-citrate was the most helpful scintigraphic agent. Both hepatic abscesses and an empyema were identified using ${ }^{67} \mathrm{Ga}$ scanning. Disadvantages of ${ }^{67} \mathrm{Ga}$ scintigraphy include the relatively long time required to complete the examination (up to $72 \mathrm{~h}$ post injection), radiation dose, and occasional problems distinguishing colon from intraabdominal abscess. An advantage of ${ }^{67} \mathrm{Ga}$ scintigraphy compared to sonography and ${ }^{99 \mathrm{~m}} \mathrm{Tc}$-sulfur colloid liver-spleen studies is the capability of wider anatomic coverage, including whole body imaging.

Computed tomography is another alternative exam in patients with suspected intraabdominal complications of CGD. CT correctly identified liver abscesses in two patients in whom the exam was obtained. In three patients who had abdominal CT, hepatosplenomegaly with liver calcifications indicative of granulomatous disease was demonstrated. Because of the advantages of ultrasonography, we do not recommend CT as the initial examination in patients with known CGD and suspected intraabdominal complications. Instead, we believe CT should be reserved for those patients with negative ultrasonograms who have compelling clinical evidence for intraabdominal infection.

In these young patients with chronic disease, non-operative management of complications is highly desirable. Using either ultrasonography or $\mathrm{CT}$, percutaneous aspiration and drainage of infected material can be accomplished obviating the need for surgery in some cases.

In summary, the newer imaging modalities of ultrasonography, CT, and nuclear medicine have proved useful in the prompt diagnosis and in some instances non-operative therapy of complications of chronic granulomatous disease.

Acknowledgement. We thank Joseph Silva, MD who followed five of these patients for many years.

\section{References}

1. Bachner RL, Nathan DG (1968) Quantitative nitroblue tetrazolium test in chronic granulomatous disease. N Engl J Med 278: 971

2. Bassani F, Capsoni F, Lazzarin A, Rossi A (1981) Chronic granulomatous disease. Pediatr Radiol 11: 105

3. Berendes H, Bridges RA, Good RA (1957) A fatal granuloma- tosis of childhood: clinical study of a new syndrome. Minn Med 40:309

4. Caldicott WJH, Baehner RL (1968) Chronic granulomatous disease of childhood. AJR 103: 133

5. Chusid MJ (1978) Pyogenic hepatic abscess in infancy and childhood. Pediatrics 62: 554

6. Dilworth JA, Mandell GL (1977) Adults with chronic granulomatous disease of "childhood". Am J Med 63: 233

7. Forbes GS, Hartman GW, Burke EC, Segura JW (1976) Genitourinary involvement in chronic granulomatous disease of childhood. AJR 127: 683

8. Gold RH, Douglas SD, Preger L, Steinbach HL, Fudenberg HH (1969) Roentgenographic features of the neutrophil dysfunction syndromes. Radiology 92: 1045

9. Griscom NT, Kirkpatrick JA, Girdany BR, Berdon WE, Grand RJ, Mackie GG (1974) Gastric antral narrowing in chronic granulomatous disease of childhood. Pediatrics 54: 456

10. Grund KE, Klotter HJ, Lemmel EM (1982) Chronische Granulomatose als seltene Ursache rezidivierender Leberabszesse. Med Welt 33: 202

11. Johansen KS, Borregaard N, Koch C, Taudorf E, Wandall JH, Repine JE (1982) Chronic granulomatous disease presenting as xanthogranulomatous pyelonephritis in late childhood. J Pediatr 100:98

12. Johnston RB, Jr, Newman SL (1977) Chronic granulomatous disease. Ped Clin North Am 24: 365

13. Landing BH, Shirkey HS (1957) A syndrome of recurrent infection and infiltration of viscera by pigmented lipid histocytes. Pediatrics 20: 431

14. Mark LK (1978) Chronic granulomatous disease in the adult. J Fam Prac 7: 445

15. Newlin N, Silver TM, Stuck KJ, Sandler MA (1981) Ultrasonic features of pyogenic liver abscesses. Radiology 139: 155

16. Preimesberger KF, Goldberg ME (1974) Acute liver abscess in chronic granulomatous disease of childhood. Radiology 110: 147

17. Quie PG, White JG, Holmes B, Good RA (1967) In vitro bactericidal capacity of human polymorphonuclear leukocytes: diminished activity in chronic granulomatous disease of childhood. J Clin Invest 46:668

18. Rutenberg WD, Yang MC, Doberstyn EB, Bellanti JA (1977) Multiple leukocyte abnormalities in chronic granulomatous disease: a familial study. Pediatr Res 11: 158

19. Samuels LD (1971) Liver scans in chronic granulomatous disease of childhood. Pediatrics 48: 41

20. Sutcliffe J, Chrispin AR (1970) Chronic granulomatous disease. Br J Radiol 43: 110

21. Wolfson JJ, Quie PG, Laxdal SD, Good RA (1968) Roentgenologic manifestations in children with a genetic defect of polymorphonuclear leukocyte function. Radiology 91: 37

22. Wolfson JJ, Kane WJ, Laxdal SD, Good RA, Quie PG (1969) Bone findings in chronic granulomatous disease of childhood. J Bone Joint Surg (Am) 51: 1573

Date of final acceptance: 1 September 1983

Dr. G. M. Glazer

Department of Radiology, Box 13

University Hospitals

Ann Arbor, Michigan 48109

USA 